\title{
Towards an Explanation of Shape of the Violin
}

\author{
Stanislaw Krupowicz \\ Karol Lipinski Academy of Music, Pl. Jana Pawla II 2, 50-043 Wroclaw, Poland
}

\begin{abstract}
Skalmierski's theory of stretched violin plates [6] is briefly described. In the course of developing a computer model for the theory, it was necessary to address the geometry of violin plates. Following Skalmierski's theory, various methods of inducing tensions into violin plates were considered. One of the most obvious, assumes that violin ribs are bent "cold", and therefore, preserve their elastic properties. The differential equations governing the large deflection of a bent beam were solved [4] and the resulting deflection curves were scaled up to match the overall dimensions of the original Stradivari violin from 1716, known as "Messiah" [2]. Three curves corresponding to the tail, middle and neck parts of the body have been assembled into half of the violin plate outline. The "Messiah" plate outline was sampled and digitized. The two curves were then compared, using various statistical tools. It was found that these two shapes were strikingly similar. The similarity is even greater, if the regions of the side blocks are omitted. The results obtained strongly support the hypothesis that Stradivari bent his violins' ribs "cold", which is in contradiction to the commonly used method in modem violin building. This confirms Skalmierski's theory, since elastically bent ribs produce counteracting forces to the compression forces of the strings. It also offers an explanation of the violin's particular shape - it is the only possible shape yielded by elastically bent ribs.
\end{abstract}

Keywords-Stradivari violin; outline of violin; stretched plates

\section{SyMBOLS AND DEFINITIONS}

$P_{A}, P_{B}, Q_{1} Q_{2}$, etc. forces

$\mathrm{M}_{\mathrm{A}}, \mathrm{M}_{\mathrm{B}}$

$\alpha_{A}, \alpha_{A}, \delta_{A}, \delta_{B}, \phi_{A}, \phi_{B}, \gamma \quad$ angles

$L_{A}, L_{B}, \quad$ length of bar parts

$l_{1}, l_{2}, l_{3}$, etc.

length of bar axis

E

Young's modules of bar

$I$

bar cross-section moment of inertia

$p, p_{A}, p_{B}$, etc. moduli of deflection

$k, k_{A}, k_{B}$, etc. elastic constants

Incomplete Legendre-Jacobi elliptic integrals of the first and second kind:

$$
F(p, \varphi)=\int_{0}^{\varphi} \frac{d t}{\sqrt{1-p^{2} \sin ^{2} t}} \quad E(p, \varphi)=\int_{0}^{\varphi} \sqrt{1-p^{2} \sin ^{2} t} d t
$$

Complete Legendre-Jacobi elliptic integrals of the first and second kind:

$$
K(p)=\int_{0}^{\pi / 2} \frac{d t}{\sqrt{1-p^{2} \sin ^{2} t}} \quad E(p)=\int_{0}^{\pi / 2} \sqrt{1-p^{2} \sin ^{2} t d t}
$$

Auxaliary functions defined in terms of elliptic integrals:

$$
\Phi(p, \phi)=2 E(p, \phi)-2 E(p)-F(p, \phi)+K(p)
$$

and

$$
\Psi(p, \phi)=2 E(p, \phi)-F(p, \phi)
$$

\section{INTRODUCTION}

\section{A. Theory of Stretched Violin Plates}

The theory of stretched violin plates [6] attempts to explain the "mystery" of old Italian violins by means of the mechanical properties of the violin body. It claims that the present-day technology of violin making is incorrect as it does not ensure a counter-tension of the sound board for the compression forces of the strings. Therefore, there must be tensions, artificially induced, to make the upper plate of a violin body resemble a drum skin, i.e. the upper plate should be stretched by the side panels and by the bottom plate.

The acoustical implications of a body constructed in this way are easy to predict, the entire violin spectrum would be shifted to the right. In order to comply with the results of Backhaus' experimental studies [1] on the spectra of violins manufactured by various luthiers, the magnitude of the forces should be selected in such a way that the main formant of the violin falls into the region of $4 \mathrm{kHz}$. As a result, the perceived sound would be brighter and louder due to the physiological (subjective) amplification of the human aural system as described by the Fletcher-Munson equal-loudness curves.

When investigating possible methods of inducing tensions into violin plates, careful consideration must be given to the dampening effects which occur in the violin body. The one resulting from the compression forces of strings is, unfortunately, inevitable. The possible methods of stretching the upper plate should minimize any additional dampening or, preferably, they should diminish that produced by the strings. Thus, for example, a tight soundpost would not be a good way to accomplish the objective proposed by the theory. One of the most obvious methods of plate stretching assumes that violin ribs are bent "cold", so that they preserve their elastic properties. 


\section{B. Ribs Bending}

A hypothesis that violin ribs were bent "cold" leads necessarily to the question of how this could have been done. There are, obviously, many answers to this question. One of the possible methods is presented in Figure I. Two clamps applied to the side corners, and one applied to the tail and neck comers would yield the necessary compressing forces. The above system can be simplified by replacing the three pairs of forces by just two: horizontal and vertical. These two methods of bending violin ribs are mechanically equivalent. To simplify the mathematics involved, it is assumed that $\mathrm{Q}$ is perpendicular to the axes $l$, as shown in Figure II. Such a system will now be investigated.

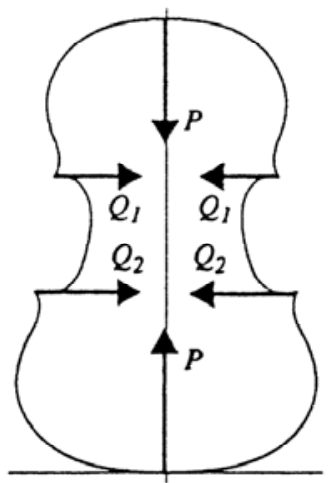

FIGURE I. VIOLINS RIBS BENT BY THREE PAIRS FORCES.

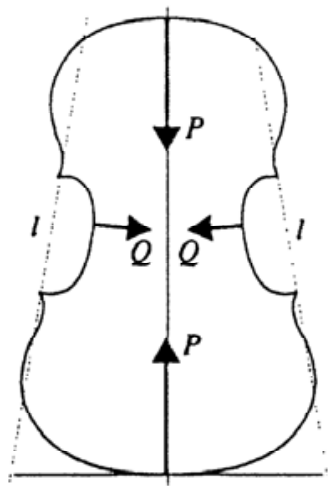

FIGURE II. VIOLINS RIBS BENT BY TWO PAIRS FORCES.

\section{DISTRIBUTION OF FORCES THROUGH VIOLIN RIBS}

The two pairs of forces $\mathrm{P}$ and $\mathrm{Q}$ will distribute through the ribs as shown in Figure III. The thick solid arrows represent external forces, thin solid arrows represent distributed forces and bending moments, and dashed arrows represent reactions. Figure III shows only one half of the violin outline; the remaining half is identical due to the violin's symmetry.

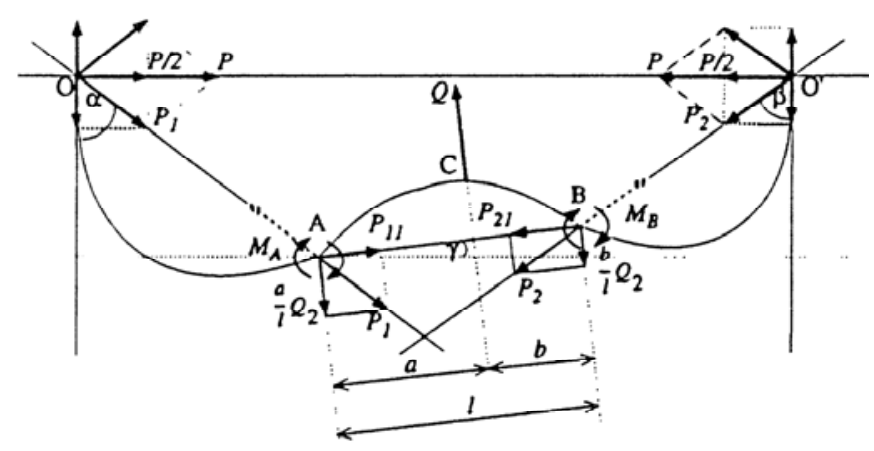

FIGURE III. DISTRIBUTION OF BENDING FORCES ALONG VIOLIN RIBS.

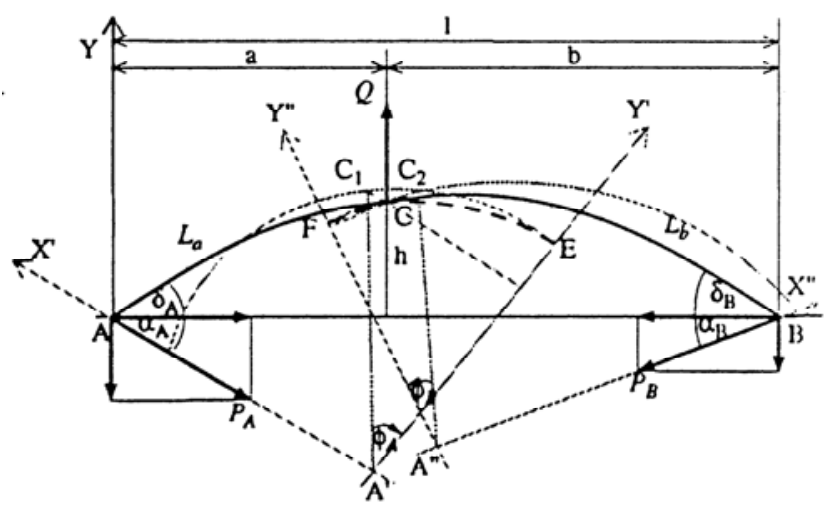

FIGURE IV. EQUILIBRIUM OF AN ELASTIC BAR SUBJECT TO THREE FORCES.

It can be seen in Figure III that the half of a violin outline OABO' is composed of three curves: OA, BO' and ACB. The first two are large deflections of a beam-column subject to an axial load, the third one is a large deflection of an elastic bar subject to three forces (see Figure IV). It seems that the contribution of the bending moments $M_{A}$ and $M_{B}$ can be neglected without losing much accuracy in the shape of the deflection curves being sought. Two such systems will now be examined.

\section{DIFFERENTIAL EQUATIONS SOLUTION}

The problem of the large deflection of a beam-column subject to an axial load has been solved by Frisch-Fay [3] and is given by the equations:

$$
\left[\begin{array}{l}
x(\varphi) \\
y(\varphi)
\end{array}\right]=\left\lceil\begin{array}{c}
\frac{\Psi(p, \varphi)}{k} \\
\frac{2 p \cos \varphi}{k}
\end{array}\right]
$$

where

$$
\varphi \ni\left[-\frac{\pi}{2}, \frac{\pi}{2}\right] \quad k=\sqrt{\frac{P}{E I}} \quad p=\sin \frac{\alpha}{2}
$$

Constant $\mathrm{k}$ and modulus $\mathrm{p}$ are defined in terms of $\mathrm{P}, \mathrm{E}, \mathrm{l}$ and slope $\alpha$ at the ends of the beam-column. The C-shaped 
middle part of a violin outline results from the bending of an elastic bar by three forces (bending moments at the ends are neglected) as shown in Figure IV. The large deflection solution for such a system is proposed in [4] and is given by two sets of parametric equations:

$$
\left[\begin{array}{l}
x_{A}(\varphi) \\
y_{A}(\varphi)
\end{array}\right]=\frac{1}{k_{A}}\left[\begin{array}{l}
2 p_{A} \cos \varphi \sin \alpha_{A}-\Phi\left(p_{A}, \varphi\right) \cos \alpha_{A} \\
2 p_{A} \cos \varphi \cos \alpha_{A}-\Phi\left(p_{A}, \varphi\right) \cos \alpha_{A}
\end{array}\right]
$$

for

$$
\varphi \ni\left\lceil\varphi_{A}, \frac{\pi}{2}\right\rceil
$$

$$
\left[\begin{array}{l}
x_{B}(\varphi) \\
y_{B}(\varphi)
\end{array}\right]=\frac{1}{k_{B}}\left[\begin{array}{c}
-2 p_{B} \cos \varphi \sin \alpha_{B}+\Phi\left(p_{B}, \varphi\right) \cos \alpha_{B}+l k_{B} \\
2 p_{B} \cos \varphi \cos \alpha_{B}-\Phi\left(p_{B}, \varphi\right) \cos \alpha_{B}
\end{array}\right]
$$

for

$$
\varphi \ni\left[\varphi_{B}, \frac{\pi}{2}\right]
$$

describing the AC and BC parts of the bar (see Figure IV), respectively. Combination of equations (2) and (3) represents the deflection curve for the entire bar ACB. These equations, however, contain nine unknown variables: $k_{A}, k_{B}, \alpha_{A}, \alpha_{B}, \phi_{A}, \phi_{B}$, $p_{A}, p_{B}$ and $l$. For obvious reasons, there is no closed-form solution for the above set of simultaneous equations. They have been, however, solved numerically with the aid of a computer.

\section{PREDICTION OF AN OUTLINE}

The outline of the real Stradivarius violin from 1716, known as "Messiah" [2] has been sampled, digitized and measured. The numerical solution to (1) has then been scaled up to match the real dimensions of the "Messiah" violin [5]. The resulting curves represent half of the tail and neck parts of the outline. They are plotted in Figure V and Figure VI, in the suitable system of the coordinates.

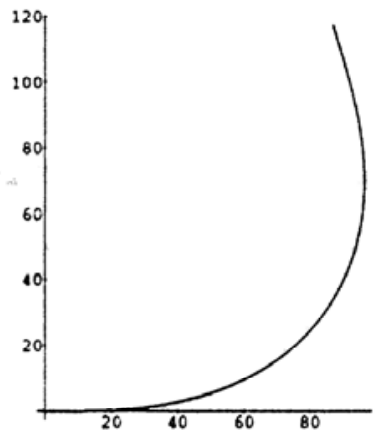

FIGURE V. PREDICTED TAIL PART OF A VIOLIN OUTLINE.

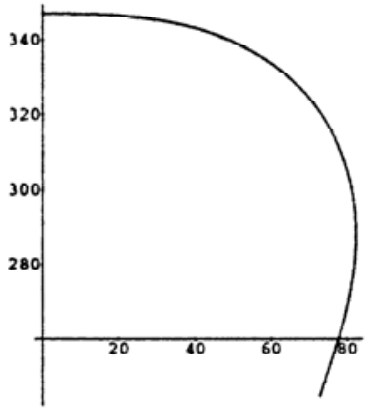

FIGURE VI. PREDICTED NECK PART OF A VIOLIN OUTLINE.

Similarly, the numerical solutions to (2) and (3) have been found. By scaling up by the measurements of the "Messiah" violin, the middle part of the violin outline has been determined. It is shown in the appropriate system of axes in Figure VII.

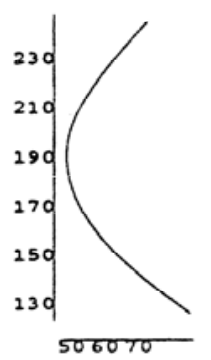

FIGURE VII. PREDICTED MIDDLE PART OF A VIOLIN OUTLINE.

The three curves described above have been assembled into half of a violin shape. Due to the symmetry of a violin, the entire outline can be now plotted (see Figure VIII).

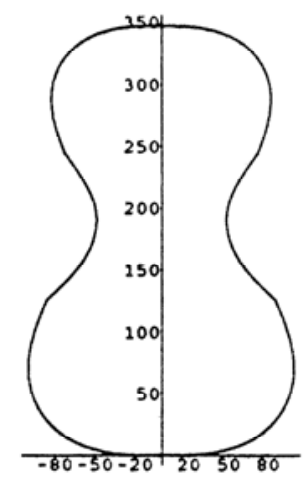

FIGURE VIII. PREDICTED OUTLINE OF STRADIVARI "MESSIAH"

\section{STATISTICAL ANALYSIS AND COMPARISON}

The outline of the real Stradivarius' instrument is plotted against the theoretically obtained curve in Figure IX. As can be seen, the similarity of these two shapes is striking. It is even greater, if the regions of the side blocks are omitted (see Figure $\mathrm{XI})$ due to the fact that the shape of ribs in these regions depends solely on the carved shape of the side blocks which can be almost arbitrarily shaped by a luthier. Therefore, the concept of elastic ribs does not hold in the vicinity of the blocks. In addition, the corner blocks to which the ribs are 
affixed, yielded some bending moments which had been neglected in the prediction.

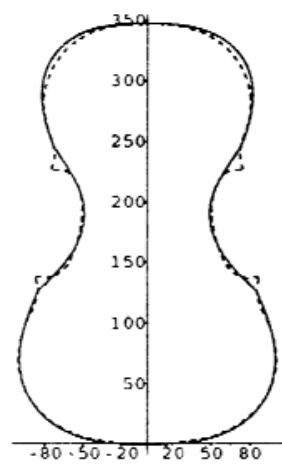

FIGURE IX. PREDICTED OUTLINE (SOLID LINE) PLOTTED AGAINST STRADIVARI'S VIOLIN (DASHED LINE) WITH THE SIDE BLOCK REGIONS INCLUDED.

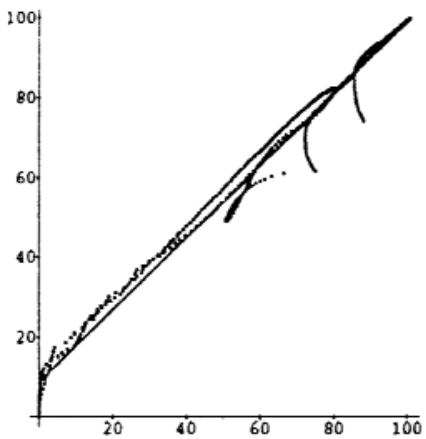

FIGURE X. REGRESSION LINE (SOLIDLINE) PLOTTED AGAINST THE SCATTERDIAGRAM (DASHED LINE) WITH THESIDE BLOCK REGIONS INCLUDED.

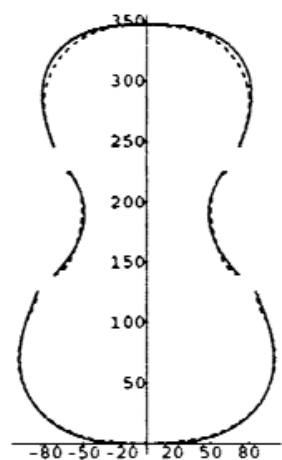

FIGURE XI. PREDICTED OUTLINE (SOLID LINE) PLOTTED AGAINST STRADIVARI'S VIOLIN (DASHED LINE) WITH THE SIDE BLOCK REGIONS EXCLUDED.

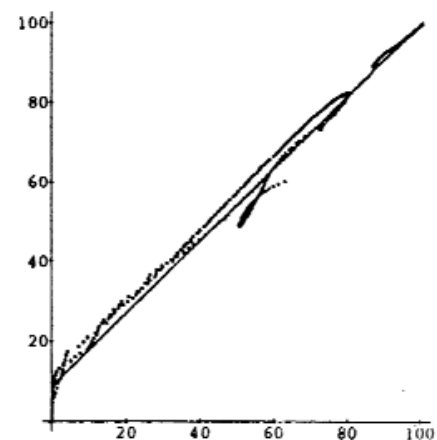

FIGURE XII. REGRESSION LINE (SOLIDLINE) PLOTTED AGAINST THE SCATTERDIAGRAM (DASHED LINE) WITH THE SIDE BLOCK REGIONS EXCLUDED.

In both cases (side block regions included and side block regions excluded), the predicted and real curves were compared using various statistical tools, yielding the following results:

TABLE I. STATISTICAL COMPARISON OF THE REAL AND THE PREDICTED OUTLINES OF STRADIVARI'S "MESSIAH."

\begin{tabular}{|l|c|c|}
\hline & $\begin{array}{c}\text { Side block regions } \\
\text { included }\end{array}$ & $\begin{array}{c}\text { Side blocks regions } \\
\text { excluded }\end{array}$ \\
\hline $\begin{array}{l}\text { Correlation } \\
\text { Coefficient }\end{array}$ & 0.91 & 0.994 \\
\hline $\begin{array}{l}\text { Regression } \\
\text { Line }\end{array}$ & $0.897 \mathrm{x}+8.765$ & $0.908 \mathrm{x}+8.607$ \\
\hline $\begin{array}{l}\text { Standard } \\
\text { Error }\end{array}$ & 3.387 & 2.740 \\
\hline
\end{tabular}

The scatter diagrams plotted against the regression lines for these two cases are presented in Figure X and Figure XII.

\section{CONCLUSION}

These results strongly support the hypothesis that Stradivari bent his violins" ribs "cold" which, in turn, supports Skalmierski's theory, since such a method of shaping a violin outline produces the counteracting forces to the compression forces of the strings. It has been experimentally checked that maple ribs of practical thickness can be bent "cold" to the shape of a violin without breaking, provided that the entire ribs outline is composed of six components.

Putting aside the question whether Stradivari indeed bent ribs of his violins in the described way, it should be noticed that there is such a possibility, and that this method would yield the desirable acoustical characteristics of a violin timbre as predicted by Skalmierski's theory. If, however, Stradivari or perhaps somebody before him, had used this method for making a violin, this would explain the violin's particular shape - it is the only possible shape of elastically bent ribs. Hence, many of the more or less poetic theories concerning the shape of the violin could be viewed as merely literary speculation, proving that reality can be more prosaic than it is believed to be which, needless to say, happens rather often.

\section{REFERENCES}

[1] H. Backhaus, "Musikinstrumente," in Handbuch der Experimentalphysik, vol 17, W. Wien and F. Harms, Eds. Technische Akustik, Teil II, E. Waetzman, Ed. Akademische Verlagsgesellschaft, Leipzig: M.B.H., 1934 
pp. 177-255.

[2] C. Fraser, Practical Violin Making. Saginaw: Chelsea Fraser, 1933.

[3] R. Frisch-Fay. Flexible Bars. Washington: Butterworths Inc., 1962.

[4] S. Krupowicz, "Large Deflection Solution for an Elastic Bar in Equilibrium Subject to Three Forces," unpublished.

[5] S. Krupowicz and B. Skalmierski. "Theory of Stretched Violin Plates and Its Implication for Violin Body Outline," in Preceedings of the 1992 CCMR Conference. Athens: CCMR, 1992.

[6] B. Skalmierski, Stan naprezenia w plytach rezonansowych a jakosc instrumentu czyli tajemnica skrzypiec. Warsaw: Panstwowe Wydawnictwo Naukowe, 1986 